\title{
Evaluation of metabolic syndromes and parasitic infection in Muscovy ducks under different management conditions
}

\author{
Isabel Chavarro-Tulcán ${ }^{1} \cdot$ Luis Alejandro Arias-Sosa $^{1}$ (D) · Alex L. $\operatorname{Rojas}^{1}$ (D)
}

Received: 6 May 2021 / Accepted: 23 September 2021 / Published online: 1 October 2021

(c) The Author(s), under exclusive licence to Springer Nature B.V. 2021

\begin{abstract}
Proper health management is essential for productivity in duck farming. However, there is limited information on the effect of management conditions on rates of metabolic problems and parasitic infections in anatids. We evaluated the rates of metabolic syndromes and gastrointestinal parasite involvement in Muscovy ducks up to 12 weeks of age, under 3 management conditions: backyard, organized, and organized with probiotics. Individuals under organized management developed 2 metabolic problems: ascites, which was rare (3.5\%), fatal, and affected both males and females, and angel wing syndrome, which was more frequent $(10.6 \%)$, has low impact on general health, and only affected males. The treatments do not have a significant effect on the development of ascites, but only individuals in controlled conditions presented this syndrome, and due to its low prevalence, further studies with a larger sample size are required. The risk of angel wing syndrome increased significantly with probiotic supplementation. Regarding to parasitic infection, the improvement of sanitary management and the use of probiotics supplementation reduced the occurrence of coccidiosis. Similarly organized management with probiotic supplementation showed a protective effect on helminthiasis by reducing the frequency of Heterakis gallinarum and greatly reducing the helminth egg load. Coccidiosis and helminthiasis infections were not significantly correlated with the final weight of the ducks. Therefore, organized management and the use of probiotics seems to reduce the impact of parasitic infection, although it increases the risk of developing metabolic syndrome.
\end{abstract}

Keywords Ascites $\cdot$ Angel wing $\cdot$ Helminthiasis $\cdot$ Coccidiosis $\cdot$ Probiotics

\section{Introduction}

Poultry production is one of the most important industries, and due to its accelerated growth, it contributes to the economic development of several countries (Windhorst 2006). This industry is dominated by chicken farming, but duck farming is also economically valuable, contributing to food security (Gariglio et al. 2019). It has grown in recent years (1998 to 2018), going from 2.6 to 4.5 million tons of meat per year (FAOSTAT 2020). Proper health management is crucial to achieve satisfactory productivity rates in the animal husbandry industry and to prevent economic losses due to morbidity and mortality (Hofacre 2002). In the case

Luis Alejandro Arias-Sosa

luisalejandro.arias@uptc.edu.co

1 Grupo Ecología de Organismos (GEO-UPTC), Escuela de Ciencias Biológicas, Universidad Pedagógica y Tecnológica de Colombia, Av. Central del Norte, 39-115, 150003 Tunja, Boyacá, Colombia of Muscovy ducks, improving management conditions has been associated with higher productivity (Baeza et al. 1997; Kleczek et al. 2006; Ramos 2009; Yakubu 2013). Despite this, the effect on health and parasitic affectation has not been studied.

Likewise, research on the use of probiotics in the poultry industry has gained significant attention due to restrictions imposed on the use of prophylactic antibiotics, given their association with microbial resistance (Kabir 2009; Hashem et al. 2019). Some studies in Muscovy ducks have reported a positive effect of novel probiotics on the development of beneficial microbiota, the restriction of pathogenic bacteria, and the improvement of productive traits (Hristev et al. 2004; Sheng-Qiu et al. 2013; Xie et al. 2015; Kamollerd et al. 2016). Similarly, several authors have studied the role of probiotic supplementation in broiler health and productivity (Lee et al. 2007a, b; Ritzi et al. 2014; Behnamifar et al. 2019). However, to our knowledge, there are no studies on the possible effect of probiotics on parasitic infection or metabolic affectations in this duck species. 
Chronic metabolic diseases are a major problem in the poultry industry. In particular, ascites is a multifactorial disorder that leads to the accumulation of fluid in the abdominal cavity and is among the most common and problematic syndromes (Part et al. 2016). This disease is frequent in production farms with high yields, since the promotion of faster growth is an important risk factor for this syndrome (Kalmar et al. 2013). The pathology, associated factors, and the effect of ascites management have been extensively studied in broiler chickens (Baghbanzadeh and Decuypere 2008; Kalmar et al. 2013; Liu 2016). However, information on chronic ascites (not infection-induced) in ducks is scarce (Julian 1988).

Another problem associated with metabolic disorders is the angel wing syndrome, a deformity that causes an outwards of one or both wings, affecting the carpometacarpus or the joint between the third and fourth metacarpals (Lin et al. 2016). This disease mainly affects waterfowl and is attributed to accelerated growth due to overfeeding in organized farming conditions (Olsen 1994). However, scientific studies or reports of the syndrome are very limited and mainly focus on geese (Lin et al. 2016). Therefore, there is a lack of information on incidence rates, the role of management conditions, etiology, and the effect on productivity in ducks.

Generally, Muscovy ducks are more resistant to infectious diseases than broiler chickens (Narvaiza 2008; Salgado-Ubeda and López-Mendonza 2012). However, some outbreaks have caused severe health problems and high mortality rates (Julian and Galt 1980; Bano et al. 2005; Mansour et al. 2018; Arias-Sosa and Rojas 2021). Even in cases of recovery, the development of diseases leads to lower growth performance and feed conversion efficiency (Glávits et al. 2005; Poonia et al. 2006; Mahardika et al. 2015). Among the infectious agents that can affect the Muscovy ducks, several gastrointestinal parasites could achieve high prevalence rates (Muhairwa et al. 2007; Mattos et al. 2008). These parasitic infections are mostly asymptomatic or associated with weakness or weight loss; but severe outbreaks of aggressive parasites such as Streptocara incognita and Haemoproteus have resulted in high mortalities in Muscovy ducks (Julian and Galt 1980; Bano et al. 2005).

We aimed to study the differences in metabolic problems and parasitic infections between three management conditions: backyard, organized, and commercial probiotics supplementation. In addition, we study the role of these problems in the weight of Muscovy ducks.

\section{Materials and methods}

\section{Study site}

The study was carried out on an organic farm in the private natural reserve "Rogitama Biodiversidad," in the municipality of Arcabuco, Boyacá, Colombia. The farm is located at an altitude between 2500 and 2550 MASL and has an average temperature of $13{ }^{\circ} \mathrm{C}$. Arcabuco has two rainy periods between April to May and September to November.

\section{Birds and management}

The birds used as breeding stock were individuals obtained from a small farm that commercialized this species in the country. Selected or imported lines were not used because the breeding of Muscovy duck in Colombia is carried out mainly in backyard conditions (Ortiz et al. 1997). The breeding stock used laid an average of $12.9 \pm 4.3$ eggs with a mean hatching rate of $76.4 \%$. They reach their sexual maturity around 6-7 months of age.

From February to August 2020, we observed the health status of Muscovy ducks, as well as the weight gain from hatching until 12 weeks of age. We selected this time period because several studies have reported an optimal slaughter time after 12 weeks for Muscovy ducks (Kleczek et al. 2006; Larzul et al. 2006; Shamma et al. 2011). A total of 91 ducklings were born during the study period, but six died during weeks one and two (6.6\% of mortality in early stages). In consequence, 85 individuals were used for our experimental design. All parental groups come from the same farm and were kept under the same conditions. Two months before the begging experiments (and egg-laying), and during the incubation period, the mothers were placed on the barn under organized and disinfected conditions. For the first 2 weeks, the ducklings were kept with their mother in an isolated, well-disinfected room and were fed with ground commercial diets containing $18 \%$ protein, $2.5 \%$ fat, $6 \%$ fiber, and $8 \%$ ashes. In the third week, we randomly assign the ducklings to one of three possible treatments:

1. Backyard conditions. This management condition simulated the common conditions of the non-technical farms that use Muscovy ducks (Avilez et al. 2007; Salgado-Ubeda and López-Mendonza 2012). The birds were kept out of the barn and fed with corn. Individuals also foraged for food (such as plant material and insects) and had greater freedom of movement. The feeding was ad libitum. The ducks had access to water for swimming and drinking in small ponds in the study area. Twentyeight individuals were assigned to this treatment.

2. Organized conditions. In this treatment, we improved sanitary conditions, reduced the mobility of the ducks, and promoted a higher feed consumption. The birds were kept inside a barn with a concrete floor covered with rice husk, curtained windows to reduce the cold at night, and a roof. Inside the barn, there were metal fences with pens that had an area of $4 \mathrm{~m}^{2}$. We randomly assigned five ducks to each of these pens and their diet 
consisted of commercial rations with $13 \%$ moisture, $19 \%$ protein, $3 \%$ fat, $5 \%$ fiber, and $8 \%$ ashes (Table 1). The feeding was ad libitum. Water was supplied in clean containers and came from a treated source. Inside the barn, a small pond was available and it was cleaned frequently, so the ducks could swim. Twenty-seven individuals were assigned to this treatment.

3. Organized conditions with probiotics supplementation. The management conditions were the same as the organized treatment condition. The only difference was the addition of commercial probiotics (Floralac), composed from Streptococcus faecium, Bifidobacterium bifidum, Lactobacillus casei, Lactobacillus acidophillus, sodium, potassium, citric acid, and ascorbic acid to their diet. The probiotics were supplied after 3 weeks in their drinking water, following the indications of the product of $1 \mathrm{~g}$ per $\mathrm{kg}$ of live weight for 5 days. Thirty individuals were assigned to this treatment.

The mean weight of the ducks at 12 weeks was $1.6 \mathrm{~kg} \pm 0.14$ for females and $2.8 \pm 0.37 \mathrm{~kg}$ for males, with a mean weekly weight gain of $149.0 \pm 513.1$ for females and $278.7 \pm 26.2 \mathrm{~g}$ for males. The health of the ducks was recorded in each treatment. We observed the respiration, absence of secretions, and state of plumage, beak, and nails. Symptoms such as weakness, weight loss, and external indications of fluid accumulation in the abdominal cavity were monitored. In dead individuals, we performed an autopsy to identify potential symptoms of ascites such as fluid accumulation in the pericardium or abdominal cavity, cardiac hypertrophy, pulmonary edema, or liver abnormalities (Baghbanzadeh and Decuypere 2008).

\section{Parasitological analysis}

After week 12, we took fecal samples from 69 individuals ( 25 from the backyard, 24 from organized, and 20 from probiotics supplementation treatments) for parasitological analysis. We were unable to sample the other 16 individuals or younger individuals due to mobility restrictions imposed during the COVID-19 emergency. For sample collections, we used sterile plastic quadrants placed under the ducks. We monitored the individuals until they defecated, then collected the samples and placed them in sterile falcon tubes. All samples were transported the same day of collection in a pre-cooled portable fridge to the laboratory for immediate processing and analysis. For parasite identification and assessment of infection frequency, we used the formol-ether technique (Larki et al. 2018), followed by staining of slides with Lugol (Badparva and Kheirandish 2017). All samples were examined under a light microscope and representative photographs were taken for the subsequent identification of the parasites based on their morphological characteristics. In addition, we assessed the parasite loads of helminth eggs and coccidia oocysts using the McMaster counting technique (Kumar et al. 2015; Bortoluzzi et al. 2018).

\section{Statistical analysis}

All data were systematized on Excel and statistical analysis was performed in free software $R$ (4.0.3 version) ( $R$ Core Team 2020). To analyze the influence of management

Table 1 Composition of the used fodders. (A) Fodders of the organized conditions treatment. (B) Fodders of the backyard conditions treatment

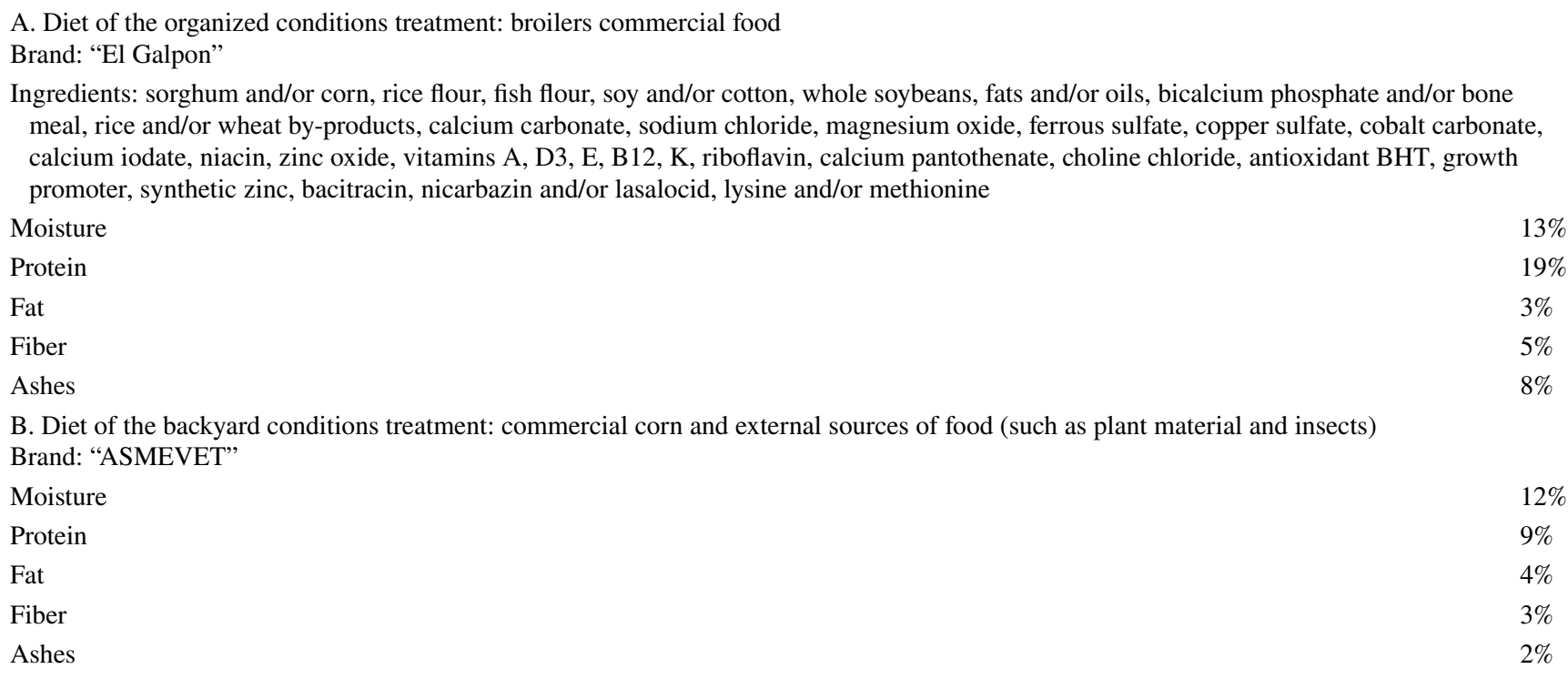


treatments on the risk of metabolic syndrome, logistic regression was used, adjusting by sex effect. The effect of the angel wing syndrome on the final weight of the Muscovy ducks was determined using generalized linear models (GLM, Gaussian response with logarithmic link, adjusting for sex and treatment). We used a post hoc Fisher pairwise test to assess the difference between each treatment.

For the parasitological analysis, we used logistic regression to evaluate the effect of treatment on parasitic frequencies and Poisson regression to study the effect on parasitic loads. For the coccidian oocyst, we fit the model using zero-inflated Poisson regression, since the count data included several zeros. We adjusted for sex in all cases. Finally, to evaluate the effect of the parasitic infection on the final weight, we used a GLM (Gaussian response with a logarithmic link) adjusting for sex. A post hoc Fisher paired test was used to assess the difference between each treatment.

\section{Results}

\section{Development of metabolic complications}

The development of metabolic problems such as ascites and angel wing syndromes was observed. Individuals with ascites presented weight loss, cyanosis in the beak and lower extremities, lethargy, ruffled plumage, fluid accumulation in the abdominal cavity, pulmonary edema, and cardiac hypertrophy (Fig. 1B). These symptoms were detected between the 8 th and 10th week. The incidence rate of ascites was $3.5 \%$ and all individuals died. In the case of angel wing syndrome, the ducks developed deformity in both wings (outward turns) at week nine. The incidence of this disorder was $10.6 \%$, but none of the individuals died. Thus, the general incidence rate was $14.1 \%$ with a mortality of $3 \%$, where ascites was rare but fatal (Fig. 1A).

The analysis showed that neither sex nor treatment significantly affected the ascites rate. However, we observed that only individuals in the organized treatments presented ascites syndrome and it was slightly higher in the group without probiotics (Fig. 1A). Both males and females were affected by this syndrome. Therefore, the restriction of mobility and promotion of higher food consumption in the individual under organized conditions appear to increase the risk of ascites problems. However, further studies with a larger sample size are required to confirm this hypothesis and to establish whether probiotics would have a significant protective effect.
Fig. 1 A Frequency of ascites and angel wing syndromes by treatments. B Representative pictures of affectation by the metabolic syndromes. $*=$ significant difference $(p<0.05)$, NS, no significant difference

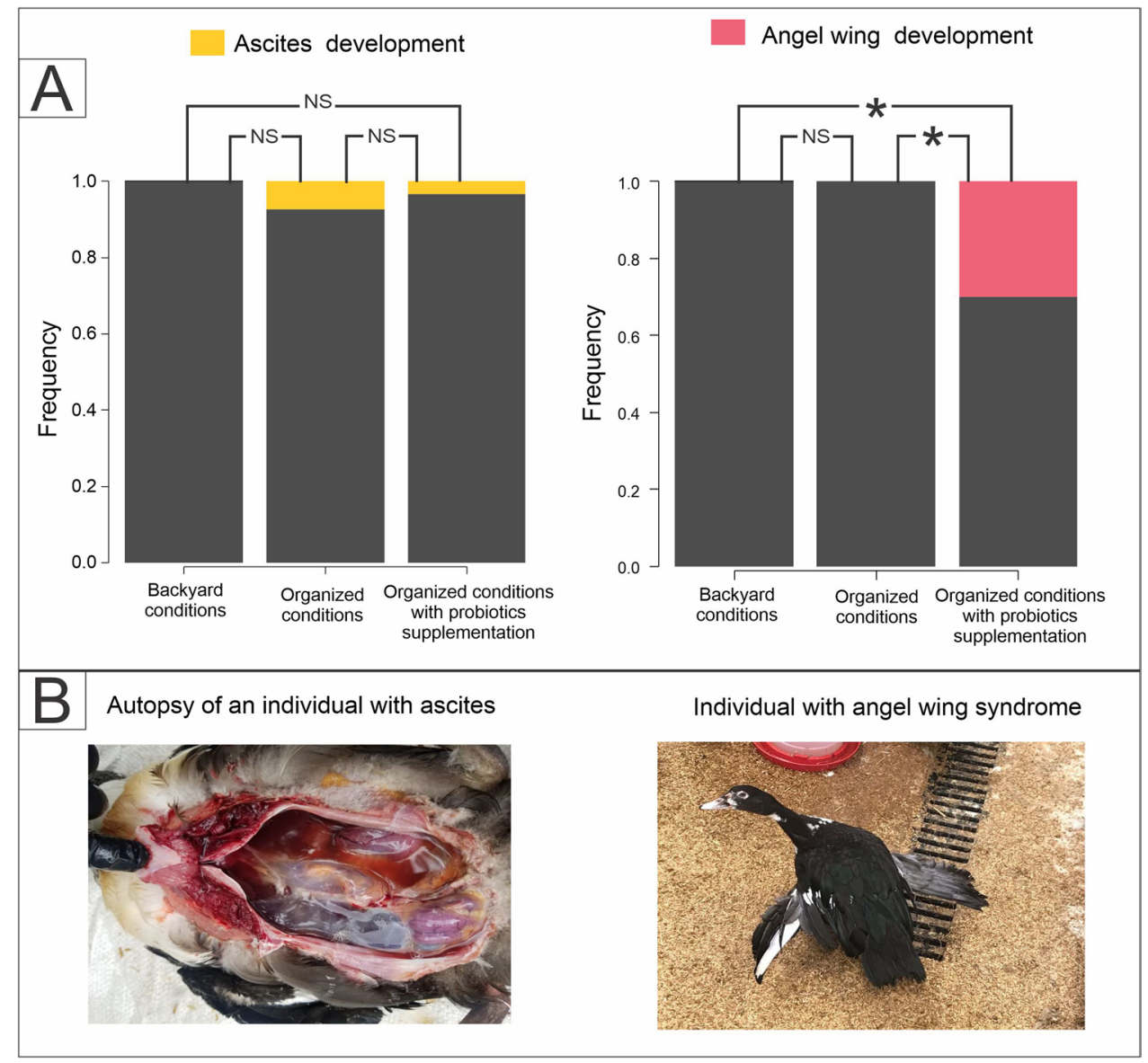


Sex and treatment influenced the prevalence of angel wing syndrome $(p<0.01)$. This syndrome occurred only in the group with organized conditions with probiotic supplementation and only male individuals were affected. However, the angel wing syndrome did not affect the final weight, when we adjusted for sex and treatment $(p>0.05)$.

\section{Parasitic infection}

The prevalence of parasites in the total sample was high $(92.7 \%)$. The most frequent parasites were coccidia (Eimeria spp.) with a prevalence of $78 \%$, followed by helminths with $65.3 \%$. We identified four classes of helminths: Ascaridia galli (46\%), Heterakis gallinarum (29\%), Strongyloides avium (16\%), and Hymenolepis spp. (6\%) (Table 2).

The frequency of coccidia was significantly affected by sex and treatment $(p<0.05)$, being higher in females than males and significantly lower in organized conditions with probiotic supplements than in backyard conditions $(p<0.01)$. The frequencies between the organized treatment without probiotics were marginally significantly lower than in the backyard conditions $(p=0.09)$. Although there were no significant differences between the organized conditions with probiotics and the organized conditions without probiotics $(p=0.17)$, a tendency to decrease in frequency was observed in the probiotic group (Fig. 2A). Coccidial oocyst loads were significantly affected by treatment $(p<0.001)$, but not by sex $(p=0.4)$. All treatments were significantly different from each other $(p<0.001)$. The highest loads were observed in backyard conditions, followed by the organized group with probiotics, and finally the organized group without probiotics (Fig. 2B). Thus, the improvement in sanitary conditions reduces the frequency and load of coccidia infection, whereas probiotic supplementation significantly reduced the coccidia frequency but increased the oocysts loads. Likewise, males showed a lower coccidia frequencies, although oocyst loads were not influenced by sex.

Table 2 Parasitic infection in different management conditions. The data of frequencies is presented as a percentage. The data of oocyst/eggs loads is presented as an average (5-95\% IQR)

\begin{tabular}{llllll}
\hline Parasite & Total frequency & A. Backyard conditions & $\begin{array}{l}\text { B. Organized conditions } \\
\text { without probiotics }\end{array}$ & $\begin{array}{l}\text { C. Organized conditions with } \\
\text { probiotics }\end{array}$ & $\begin{array}{l}\text { GLM } p \text {-value } \\
\text { Eimeria spp. }\end{array}$ \\
\hline Ascaridia galli & $78 \%$ & $96 \%^{\mathrm{c}}$ & $79 \%$ & $55 \%^{\mathrm{a}}$ & $p<0.05^{*}$ \\
Heterakis gallinarum & $29 \%$ & $48 \%$ & $54 \%$ & $35 \%$ & $p>0.05$ \\
Strongyloides avium & $16 \%$ & $44 \%^{\mathrm{c}}$ & $21 \%$ & $5 \%^{\mathrm{a}}$ & $p<0.05^{*}$ \\
Hymenolepis spp. & $6 \%$ & $16 \%$ & $25 \%$ & $5 \%$ & $p>0.05$ \\
Type of infection & Average number & A. Backyard conditions & B. Organized conditions & C. Organized conditions with & GLM $p$-value \\
& of oocyst/eggs & & without probiotics & probiotics & \\
Coccidiosis & $73.9(0-330)$ & $170(0-550)$ & $4.2(0-42.5)$ & $37.5(0-107.5)$ & $p<0.001^{*}$ \\
Helminthiasis & $633.3(17-1330)$ & $728(200-1430)$ & $714.6(67.2-1277.5)$ & $417.5(4.7-1302)$ & $p<0.001^{*}$ \\
\hline
\end{tabular}

Fig. 2 A Coccidia frequencies by treatment. B Coccidia oocyst loads by treatment. $*=$ significant difference $(p<0.05)$, MS, marginally significant $(p=0.05-0.1)$. NS, no significant difference

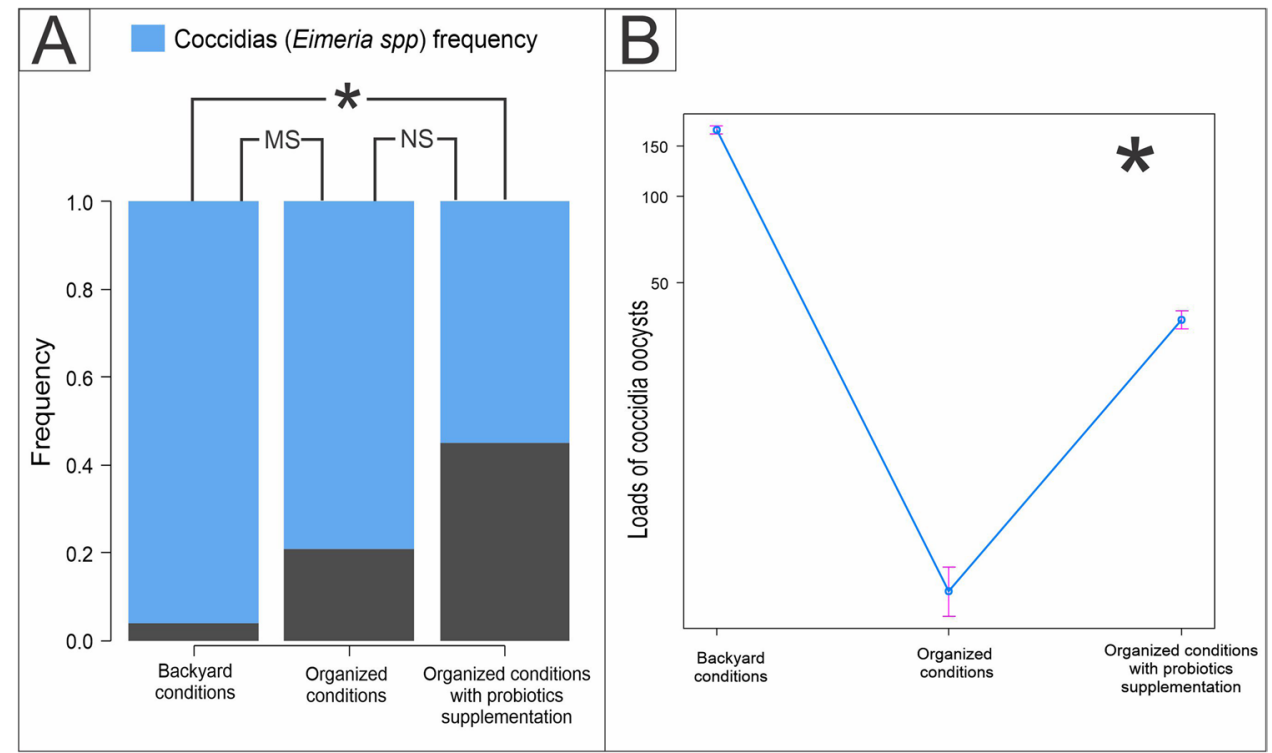


In helminths, we only observed a significant effect of the treatment on the infection frequency of $\mathrm{H}$. gallinarum $(p<0.01)$, but it was not affected by the sex of the ducks $(p>0.05)$. The backyard conditions group presented a significantly higher frequency of $H$. gallinarum than the organized group with probiotic supplementation ( $p=0.01$ ), as well as a marginally higher frequency than the group without probiotics $(p=0.08)$. However, there were no significant differences between the organized conditions group with probiotics and without probiotics $(p=0.17)$, and a trend towards a lower frequency was observed in the probiotic (Fig. 3A). The presence of other species of helminths was not significantly affected by sex or treatment $(p>0.05)$, but a low impact on probiotic management was observed in all of them (Fig. 3). On the other hand, helminth egg loads were significantly influenced by sex and treatment $(p<0.01)$, and the females presented higher loads than males. All management groups were significantly different from each other $(p<0.001)$. The highest loads were found in the backyard conditions, decreasing in the organized conditions without probiotics, and reaching a large reduction in the individuals supplemented with probiotics. Thus, the improvement of management conditions and the use of probiotics has a significant protective effect against $H$. gallinarum, showing a tendency to reduce the affectation by other species of helminths, and a decrease in the helminth egg loads. The final weight was only affected by the sex $(p<0.001)$, being higher in males than females, while the loads of coccidia oocytes and helminth eggs did not have a significant effect $(p>0.05)$.

\section{Discussion}

The relative frequency of ascites problems in our study (3\%) was similar to the 4-6\% reported in well-managed broiler farms (Baghbanzadeh and Decuypere 2008; Feizi et al. 2012). However, it was lower (23-53\%) than reports from broiler exposed to cold stress conditions $\left(12-16{ }^{\circ} \mathrm{C}\right)$ (Wideman et al. 1998; van As et al. 2010), which are similar to our studied farm conditions (average temperature of $13{ }^{\circ} \mathrm{C}$ ). Programs that increase feed consumption and the use of commercial diets in broilers have been associated with an increased risk of ascites (Avila González et al. 2006; Khajali and Wideman 2016). This is consistent with our result, where it was found that only ducks in organized conditions presented this syndrome. The use of probiotics in broiler chickens has a positive effect on the prevention of ascites (Saffar and Khajali 2010; Kalia et al. 2017). In our study, we found a slightly lower incidence in individuals treated with probiotics, although it was not statistically significant. Therefore, more studies with larger sample sizes are required to evaluate the effect of probiotics, especially since the incidence of the disease is low.
The incidence of angel wing syndrome was $10.6 \%$, much lower than the 39\% reported in a white Roman geese farm (Lin et al. 2016). A diet that promotes faster growth has been suggested to be the main cause of angel wing development (Olsen 1994; Lin et al. 2016), and this is consistent with the development of this syndrome only in the organized group with probiotics supplementation, although in our study, only males developed this syndrome. A similar observation has been reported for swans (Cygnus cygnus and Cygnus atratus) since males presented a higher risk of angel wing development than females (Arican et al. 2019). The high affectation in male Muscovy ducks is probably due to the fact that in this duck, the male presents a noticeably greater and faster weight gain than the female (Larzul et al. 2006; Shamma et al. 2011). However, we did not find other studies on the incidence of the disease or the relationship with management conditions in ducks to compare with our results.

There are some studies on parasitological infection in Muscovy ducks. Nevertheless, these are mainly focused on parasitological surveys (Woodyard and Bolen 1984; Muhairwa et al. 2007; Mattos et al. 2008; Hoque et al. 2014), while the studies in relation to parasitic infections with management conditions and productive traits are limited for anatids. The incidence of gastrointestinal parasites (92.7\%) was higher than in other research of the same species, which are around 52-57\% (Muhairwa et al. 2007; Mattos et al. 2008). This probably happens because multiple farms with different incidences have been sampled in previous studies, and parasitic infections are more common on organic farms like the ones we studied (Gocsik et al. 2014). Unlike our results, a previous study in Muscovy ducks showed a higher affectation by helminths and a low prevalence of coccidias (Hoque et al. 2014). However, other reports on Pekin ducks showed a higher frequency of coccidiosis than helminthiasis (Jayentakumar Singh and Mohilal 2017). Like our results, other reports have indicated that the most common helminths affecting the Muscovy ducks are Ascaridia galli and Heterakis gallinarum (Muhairwa et al. 2007; Hoque et al. 2014). Only one study in Mexico reported the presence of Hymenolepis spp. in this duck (Woodyard and Bolen 1984), and in the case of Strongyloides avium infections, no other investigations have been found.

We observed that the incidence of coccidia was higher in females than in male ducks. Differences in coccidiosis between sexes have been reported in broiler chickens (Ola-Fadunsin 2017). The frequency and loads of coccidiosis were higher in backyard conditions compared to the organized groups. Studies in broilers under disorganized or backyard conditions showed higher affectations of coccidiosis compared to organized or commercial farms, since the sanitary and environmental conditions of backyard farms facilitate infection (Sharma et al. 2013; Fatoba and Adeleke 2018). We did not find a significant effect of coccidial infection on 
Fig. 3 A Helminth frequencies by treatment. B Helminth egg loads by treatment. $*=$ significant difference $(p<0.05)$, NS, no significant differences $(p>0.1)$, MS, marginally significant $(p=0.05-0.1)$

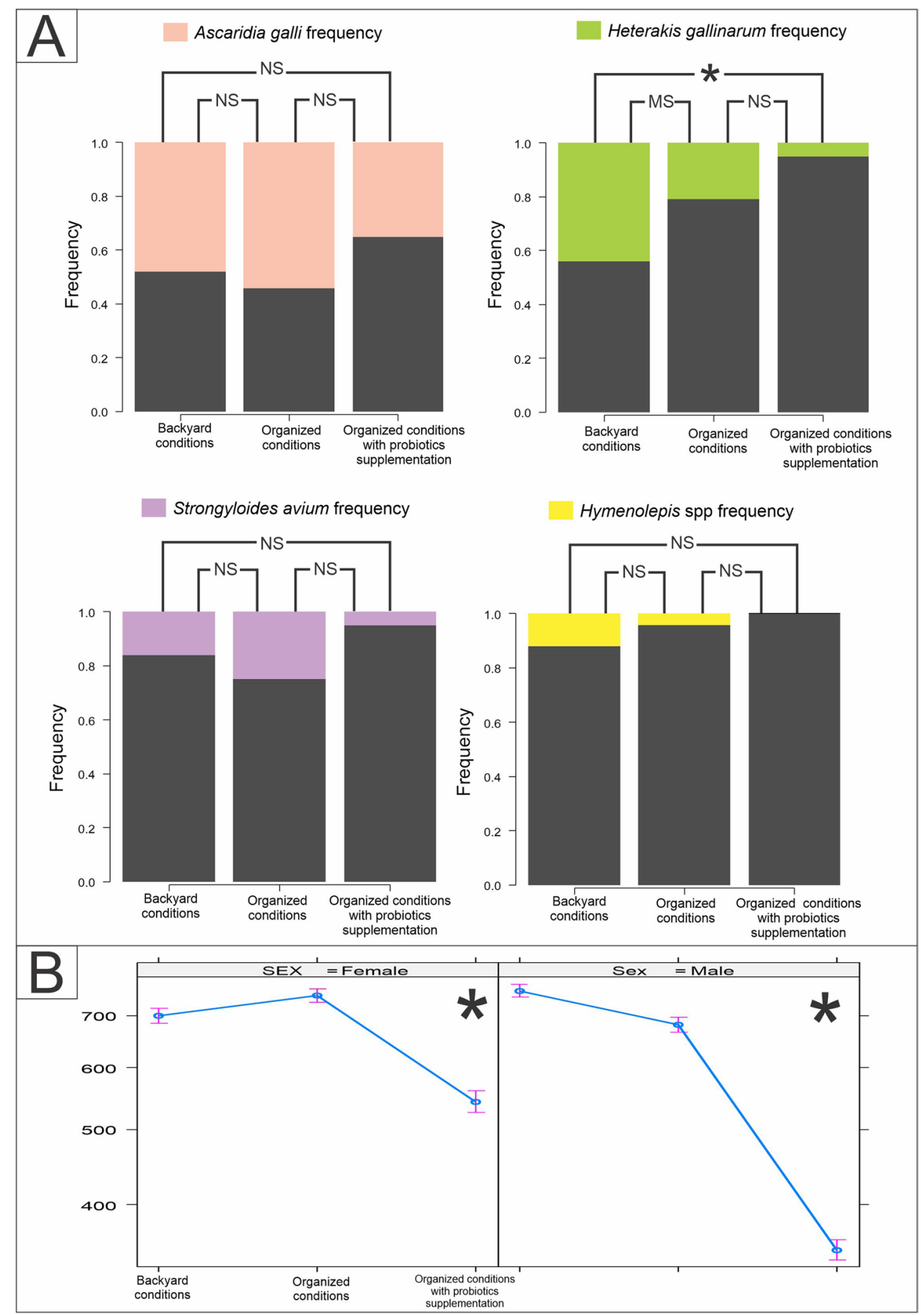

the final weight of the ducks. However, a previous study of experimental Eimeria mulardi infection showed a decreased in the growth of Muscovy ducks (Sercy et al. 1996). Therefore, further studies are required to better assess the effect of coccidiosis on the growth performance of this duck.

Probiotics showed significant protection against coccidiosis, reducing the frequency of infection but without decreasing the oocyst loads. Other studies in broilers established a significant protective effect of probiotics against coccidiosis infection and a reduction in the coccidia oocysts loads (S. H. Lee et al. 2007a, b; Ritzi et al. 2014). Although we did not find studies on the role of probiotics for parasitic infection in ducks, there are some reports on their efficacy against pathogenic bacteria (Hristev et al. 2004; Nickolova and Penkov 2005; Sheng-Qiu et al. 2013). Our research showed that probiotics can be a useful tool in protecting against coccidiosis in Muscovy ducks, and further studies are required to understand the effect on oocyst loads. 
We found that organized conditions with probiotic supplementation reduced the frequency of $H$. gallinarum and significantly reduced loads of helminth eggs in feces samples. The use of commercial probiotics was helpful for the prevention of helminthiasis in Muscovy ducks. Our results are consistent with the positive effect of supplementation with probiotics that reduce helminth infections in different animal models (Bucková et al. 2018; Leung et al. 2018; Reda 2018). A similar study in laying hens reported a lower frequency of helminth infection in individuals treated with probiotics (Shini et al. 2013). No significant association was found between helminth egg load and duck weight gain. Likewise, some studies in chickens indicate that helminthiasis is not significantly associated with reduced productivity traits (Gauly et al. 2008; Sharma et al. 2018). However, other researchers have found that helminthiasis has detrimental effects on growth performance and feed intake in chickens (Phiri et al. 2007; Daş et al. 2012; Katoch et al. 2012; Stehr et al. 2019). For this reason, it is important to carry out research to establish the effect of helminthiasis on the productive performance of Muscovy ducks.

\section{Conclusion}

Our results indicate that the organized conditions with probiotic supplementation are recommended in the breeding of Muscovy ducks due to the protective effect on parasitic infection. Likewise, it could reduce ascites incidence, but more studies with larger sample sizes are required since no statistically significant differences were found and the incidence of the disease was low. Moreover, additional strategies for angel wing syndrome prevention are required for this type of poultry farming system, because the potential effect of faster weight gain with probiotics increases the risk of this syndrome.

\footnotetext{
Author contribution All authors contributed to the study conception and design. Material preparation, data collection, and analysis were performed by Isabel Chavarro-Tulcán and Luis Alejandro Arias-Sosa. The first draft of the manuscript was written by Luis Alejandro AriasSosa and Alex L. Rojas. The supervision and review of the article were made by Alex L. Rojas.
}

Funding This study was funded by the "Universidad Pedagógica y Tecnológica de Colombia," the "Ministerio de Ciencia Tecnología e Innovación," and the "Gobernacion de Boyacá" under project code 66071 "Potencial productivo del pato criollo (Cairina moschata) como altemativa agroindustrial y alimentaria del municipio de Arcabuco, Boyacá.” Grant number 80740-560-2019, SGI 2633.

Availability of data and material Data is available within the article or its supplementary materials. Additional data will be shared with a reasonable request to the corresponding author.

\section{Declarations}

Ethics approval This research was approved by the UPTC ethics committee.

Conflict of interest The authors declare no competing interests.

\section{References}

Arias-Sosa, L.A. and Rojas, A.L., 2021. A review on the productive potential of the Muscovy Duck, World's Poultry Science Journal, 77(3), 565-588

Arican, M., Parlak, K. and Yalçin, M., 2019. Angel wings syndrom in swans (Cygnus cygnus and cygnus atratus), Kafkas Universitesi Veteriner Fakultesi Dergisi, 25, 873-877

Avila González, E., Cortés Cuevas, A. and Estrada Contreras, A., 2006. Productividad y mortalidad por síndrome ascítico en pollos de engorda alimentados con dietas granuladas o en harina, Técnica Pecuaria en México, 44, 241-246

Avilez, J., Aillapan, O.A., Perea Falcón, J., Rodríguez, V. and García, A., 2007. Sistemas de alimentación de patos muscovy ("carina moschata") en agricultores mapuches chilenos, Archivos de Zootecnia, 56, 503-506

Badparva, E. and Kheirandish, F., 2017. Epidemiology of pathogenic parasite Histomonas meleagridis in poultry in Lorestan province, western Iran, Journal of Parasitic Diseases, 41, 1040-1043

Baeza, E., De Carville, H., Salichon, M.R., Marche, G. and Leclercq, B., 1997. Effects of selection, over three and four generations, on meat yield and fatness in Muscovy ducks, British Poultry Science, $38,359-365$

Baghbanzadeh, A. and Decuypere, E., 2008. Ascites syndrome in broilers: Physiological and nutritional perspectives, Avian Pathology, $37,117-126$

Bano, L., Natale, A., Vascellari, M., Comin, D., Mutinelli, F. and Agnoletti, F., 2005. First report of parasitic esophagitis by Streptocara incognita in Muscovy ducks (Cairina moschata domesticus) in Italy., Avian diseases, 49, 298-300

Behnamifar, A.R., Rahimi, S., Kiaei, M.M. and Fayazi, H., 2019. Comparison of the effect of probiotic, prebiotic, salinomycin and vaccine in control of coccidiosis in broiler chickens., Iranian journal of veterinary research, 20, 51-54

Bortoluzzi, C., Paras, K.L., Applegate, T.J. and Verocai, G.G., 2018. Comparison between McMaster and Mini-FLOTAC methods for the enumeration of Eimeria maxima oocysts in poultry excreta, Veterinary Parasitology, 254, 21-25

Bucková, B., Hurníková, Z., Lauková, A., Revajová, V. and Dvorožňáková, E., 2018. The anti-parasitic effect of probiotic bacteria via limiting the fecundity of Trichinella spiralis female adults, Helminthologia (Poland), 55, 102-111

Daş, G., Abel, H., Humburg, J., Schwarz, A., Rautenschlein, S., Breves, G. and Gauly, M., 2012. The effects of dietary non-starch polysaccharides on Ascaridia galli infection in grower layers, Parasitology, 139, 110-119

FAOSTAT, 2020. Livestock Primary

Fatoba, A.J. and Adeleke, M.A., 2018. Diagnosis and control of chicken coccidiosis: a recent update, Journal of Parasitic Diseases, $42,483-493$

Feizi, A., Bijanzad, P., Kaboli, K. and Moghaddam, amid reza jeyrani, 2012. Comparative Survey Of Ascites Syndrome Incidence Rate In Various Strains Of Broiler Chickens, Australian Journal of Basic and Applied Sciences, 6, 185-191 
Gariglio, M., Dabbou, S., Biasato, I., Capucchio, M.T., Colombino, E., Hernández, F., Madrid, J., Martínez, S., Gai, F., Caimi, C., Oddon, S.B., Meneguz, M., Trocino, A., Vincenzi, R., Gasco, L. and Schiavone, A., 2019. Nutritional effects of the dietary inclusion of partially defatted Hermetia illucens larva meal in Muscovy duck, Journal of Animal Science and Biotechnology, 10, 37

Gauly, M., Kanan, A., Brandt, H., Weigend, S., Moors, E. and Erhardt, G., 2008. Genetic resistance to Heterakis gallinarum in two chicken layer lines following a single dose infection, Veterinary Parasitology, 155, 74-79

Glávits, R., Zolnai, A., Szabó, É., Ivanics, É., Zarka, P., Mató, T. and Palya, V., 2005. Comparative pathological studies on domestic geese (Anser Anser Domestica) and muscovy ducks (Cairina Moschata) experimentally infected with parvovirus strains of goose and muscovy duck origin, Acta Veterinaria Hungarica, 53, 73-89

Gocsik, É., Kortes, H.E., Lansink, A.G.J.M.O. and Saatkamp, H.W., 2014. Effects of different broiler production systems on health care costs in the Netherlands, Poultry Science, 93, 1301-1317

Hashem, M.A., Neamat-Allah, A.N.F., Hammza, H.E.E. and AbouElnaga, H.M., 2019. Impact of dietary supplementation with Echinacea purpurea on growth performance, immunological, biochemical, and pathological findings in broiler chickens infected by pathogenic E. coli, Tropical Animal Health and Production 2019 $52: 4,52,1599-1607$

Hofacre, C.L., 2002. The health and management of poultry production, International Journal of Infectious Diseases, 6, 90177-3

Hoque, M.A., Hassan, M.M., Haque, E., Shaikat, A.H., Khan, S.A., Alim, A., Skerratt, L.F., Islam, A., Tun, H.M., Dissanayake, R., Day, T.K., Debnath, N.C. and Yamage, M., 2014. A survey of gastro-intestinal parasitic infection in domestic and wild birds in Chittagong and Greater Sylhet, Bangladesh, Preventive Veterinary Medicine, 117, 305-312

Hristev, H., Bochukov, A. and Pechev, G., 2004. Comparative study on the effect of Lactina ${ }^{\circledR}$ probiotic on some microbiological and histological characteristics of the digestive tract of Muscovy ducklings, Journal of Central European Agriculture, 5, 347-352

Jayentakumar Singh, L. and Mohilal, N., 2017. Gastrointestinal parasitic infection in diverse species of domestic birds of Manipur, India, Journal of Parasitic Diseases, 41, 142-146

Julian, R.J., 1988. Ascites in meat-type ducklings, Avian Pathology, $17,11-21$

Julian, R.J. and Galt, D.E., 1980. Mortality in muscovy ducks (Cairina moschata) caused by Haemoproteus infection., Journal of wildlife diseases, 16, 39-44

Kabir, S.M.L., 2009. The role of probiotics in the poultry industry, International Journal of Molecular Sciences, 10, 3531-3546

Kalia, S., K Bharti, V., Gogoi, D., Giri, A. and Kumar, B., 2017. Studies on the growth performance of different broiler strains at high altitude and evaluation of probiotic effect on their survivability., Scientific reports, 7, 46074

Kalmar, I.D., Vanrompay, D. and Janssens, G.P.J., 2013. Broiler ascites syndrome: Collateral damage from efficient feed to meat conversion, Veterinary Journal, 197, 169-174

Kamollerd, C., Surachon, P., Maunglai, P., Siripornadulsil, W. and Sukon, P., 2016. Assessment of probiotic potential of Lactobacillus reuteri MD5-2 isolated from ceca of Muscovy ducks, Korean Journal of Veterinary Research, 56, 1-7

Katoch, R., Yadav, A., Godara, R., Khajuria, J.K., Borkataki, S. and Sodhi, S.S., 2012. Prevalence and impact of gastrointestinal helminths on body weight gain in backyard chickens in subtropical and humid zone of Jammu, India, Journal of Parasitic Diseases, 36, 49-52

Khajali, F. and Wideman, R.F., 2016. Nutritional approaches to ameliorate pulmonary hypertension in broiler chickens, Journal of Animal Physiology and Animal Nutrition, 100, 3-14
Kleczek, K., Wawro, K., Wilkiewicz-Wawro, E. and Makowski, W., 2006. Multiple regression equations to estimate the content of breast muscles, meat, and fat in Muscovy ducks, Poultry Science, $85,1318-1326$

Kumar, S., Garg, R., Ram, H., Maurya, P.S. and Banerjee, P.S., 2015. Gastrointestinal parasitic infections in chickens of upper gangetic plains of India with special reference to poultry coccidiosis., Journal of parasitic diseases : official organ of the Indian Society for Parasitology, 39, 22-6

Larki, S., Alborzi, A., Chegini, R. and Amiri, R., 2018. A preliminary survey on gastrointestinal parasites of domestic Ducks in Ahvaz, Southwest Iran, Iranian Journal of Parasitology, 13, 137-144

Larzul, C., Imbert, B., Bernadet, M.-D., Guy, G. and Rémignon, H., 2006. Meat quality in an intergeneric factorial crossbreeding between muscovy ( Cairina moschata ) and Pekin ( Anas platyrhynchos ) ducks, Animal Research, 55, 219-229

Lee, S., Lillehoj, H.S., Park, D.W., Hong, Y.H. and Lin, J.J., 2007a. Effects of Pediococcus- and Saccharomyces-based probiotic (MitoMax ${ }^{\circledR)}$ on coccidiosis in broiler chickens, Comparative Immunology, Microbiology and Infectious Diseases, 30, 261-268

Lee, S.H., Lillehoj, H.S., Dalloul, R.A., Park, D.W., Hong, Y.H. and Lin, J.J., 2007b. Influence of Pediococcus-based probiotic on coccidiosis in broiler chickens, Poultry Science, 86, 63-66

Leung, J.M., Graham, A.L. and Knowles, S.C.L., 2018. Parasite-microbiota interactions with the vertebrate gut: Synthesis through an ecological lens,

Lin, M.J., Chang, S.C., Lin, T.Y., Cheng, Y.S., Lee, Y.P. and Fan, Y.K., 2016. Factors affecting the incidence of angel wing in white roman geese: Stocking density and genetic selection, Asian-Australasian Journal of Animal Sciences, 29, 901-907

Liu, W., 2016. A trial diagnosis of ascites syndrome in broiler chickens, Pakistan Journal of Biological Sciences, 19, 352-359

Mahardika, G.N., Permana Ardiana, P.M.B.A., Dewi, N.P.S., Dewi, N.M.R. and Winaya, I.B.O., 2015. Muscovy Duck Parvovirus Infection with Epicarditis in Bali, Indonesia, Journal of Veterinary Science \& Technology, 07, 1-5

Mansour, S.M.G., Ali, H., ElBakrey, R.M., El-Araby, I.E., Knudsen, D.E.B. and Eid, A.A.M., 2018. Co-infection of highly pathogenic avian influenza and duck hepatitis viruses in Egyptian backyard and commercial ducks, International Journal of Veterinary Science and Medicine, 6, 301-306

Mattos, D.G. de, Costa, D. de A. da, Menezes, R.C. and Mesquita, E.M., 2008. Prevalência de helmintos em patos domésticos Cairina moschata dom. (Linné) (Anseriformes, Anatidae, Cairinini, Cairina) provenientes de criações extensivas no estado do Rio de Janeiro, Brasil, Revista Brasileira de Ciência Veterinária, 15, $140-142$

Muhairwa, A.P., Msoffe, P.L., Ramadhani, S., Mollel, E.L., Mtambo, M.M.A. and Kassuku, A.A., 2007. Prevalence of gastro-intestinal helminths in free-range ducks in Morogoro Municipality, Tanzania, Livestock Research for Rural Development, 19, 48

Nickolova, M. and Penkov, D., 2005. Experimental influence of Laktina ${ }^{\circledR}$ probiotic on egg laying characteristics, fertility and viability in Muscovy duck (Cairina moshcata)., Journal of Central European Agriculture, 5, 353-358

Ola-Fadunsin, S.D., 2017. Investigations on the Occurrence and Associated Risk Factors of Avian Coccidiosis in Osun State, Southwestern Nigeria, Journal of Parasitology Research, 2017, 6

Olsen, J.H., 1994. Ansriformes, In:, W. R. Branson, G. J. Harrison , and L. R. Harrison (eds), Avian Medicine: Principles and Applications, (Wingers Publishing: Florida), 1257-1258

Ortiz, S.G., Rodriguez, C., Alvarez, L. and Escobar, J., 1997. Curva de crecimiento y rendimiento carnico de patos Muscovy 
Cairina moschata L. en condiciones de cria y ceba intensiva, Acta Agronómica, 47, 33-38

Part, C.E., Edwards, P., Hajat, S. and Collins, L.M., 2016. Prevalence rates of health and welfare conditions in broiler chickens change with weather in a temperate climate, Royal Society Open Science, 3, 160197

Phiri, I.K., Phiri, A.M., Ziela, M., Chota, A., Masuku, M. and Monrad, J., 2007. Prevalence and distribution of gastrointestinal helminths and their effects on weight gain in free-range chickens in Central Zambia, Tropical Animal Health and Production, 39, 309-315

Poonia, B., Dunn, P., Lu, H., Jarosinski, K.W. and Schat, K.A., 2006. Isolation and molecular characterization of a new Muscovy duck parvovirus from Muscovy ducks in the USA, Avian Pathology, 35, 435-441

R Core Team, 2020. R: A language and environment for statistical computing, (R Foundation for Statistical Computing: Vienna, Austria)

Ramos, M.A., 2009. Evaluación de algunos parámetros productivos del pato real (Cairina moschata) en un sistema de cría semintensiva, (Universidad Central de Venezuela)

Reda, A.A., 2018. Probiotics for the Control of Helminth Zoonosis, Journal of Veterinary Medicine, 2018, 1-9

Ritzi, M.M., Abdelrahman, W., Mohnl, M. and Dalloul, R.A., 2014. Effects of probiotics and application methods on performance and response of broiler chickens to an Eimeria challenge, Poultry Science, 93, 2772-2778

Saffar, A. and Khajali, F., 2010. Application of meal feeding and skip-a-day feeding with or without probiotics for broiler chickens grown at high-altitude to prevent ascites mortality, American Journal of Animal and Veterinary Sciences, 5, 13-19

Salgado-Ubeda, M. and López-Mendonza, J.C., 2012. Crianza de patos domésticos (Cairina moschata) en la comunidad Piedra Colorada, Matagalpa. Estudio de caso., (Universidad Nacional agraria)

Sercy, O., Nie, K., Pascalon, A., Fort, G. and Yvore, P., 1996. Receptivity and Susceptibility of the Domestic Duck (Anas platyrhynchos), the Muscovy Duck (Cairina moschata), and Their Hybrid, the Mule Duck, to an Experimental Infection by Eimeria mulardi, Avian Diseases, 40, 23-27

Shamma, T.A., Khalifa, H.H. and Abougabal, M.S., 2011. Meat production and force feeding ability of Muscovy ducks under Egyptian condition., Al-Azhar Journal of Agricultural Research, 400, 1-15

Sharma, S., Iqbal, A., Azmi, S., Mushtaq, I., Wani, Z.A. and Ahmad, S., 2013. Prevalence of poultry coccidiosis in Jammu region of Jammu \& Kashmir State, Journal of Parasitic Diseases, 39, 85-89
Sharma, N., Hunt, P.W., Hine, B.C., Sharma, N.K., Chung, A., Swick, R.A. and Ruhnke, I., 2018. Performance, egg quality, and liver lipid reserves of free-range laying hens naturally infected with Ascaridia galli, Poultry Science, 97, 1914-1921

Sheng-Qiu, T., Xiao-Ying, D., Chun-Mei, J., Jing-Jing, P., Shan-Shan, L. and Jin-Ding, C., 2013. Effect of Bacillus subtilis natto on growth performance in Muscovy ducks, Revista Brasileira de Ciência Avícola, 15, 191-197

Shini, S., Shini, A. and Blackall, P.J., 2013. The potential for probiotics to prevent reproductive tract lesions in free-range laying hens, Animal Production Science, 53, 1298

Stehr, M., Zentek, J., Vahjen, W., Zitnan, R., Tuchscherer, A., Gauly, M., Metges, C.C. and Daş, G., 2019. Resistance and tolerance to mixed nematode infections in chicken genotypes with extremely different growth rates, International Journal for Parasitology, 49, 579-591

van As, P., Elferink, M.G., Closter, A.M., Vereijken, A., Bovenhuis, H., Crooijmans, R.P.M.A., Decuypere, E. and Groenen, M.A.M., 2010. The use of blood gas parameters to predict ascites susceptibility in juvenile broilers, Poultry Science, 89, 1684-1691

Wideman, R.F., Wing, T., Kirby, Y.K., Forman, M.F., Marson, N., Tackett, C.D. and Ruiz-Feria, C.A., 1998. Evaluation of Minimally Invasive Indices for Predicting Ascites Susceptibility in Three Successive Hatches of Broilers Exposed to Cool Temperatures, Poultry Science, 77, 1565-1573

Windhorst, H.-W., 2006. Changes in poultry production and trade worldwide, World's Poultry Science Journal, 62, 585-602

Woodyard, E.R. and Bolen, E.G., 1984. Ecological Studies of Muscovy Ducks in Mexico, The Southwestern Naturalist, 29, 453-461

Xie, Z.L., Bai, D.P., Xie, L.N., Zhang, W.N., Huang, X.H. and Huang, Y.F., 2015. Intestinal lactic acid bacteria from Muscovy duck as potential probiotics that alter adhesion factor gene expression, Genetics and Molecular Research, 14, 12262-12275

Yakubu, A., 2013. Characterisation of the local Muscovy duck in Nigeria and its potential for egg and meat production, World's Poultry Science Journal, 69, 931-938

Publisher's Note Springer Nature remains neutral with regard to jurisdictional claims in published maps and institutional affiliations. 